\title{
Compostos indólicos com potencial anticâncer: desenvolvimentos mais recentes
}

Indolic compounds with anticancer potential: latest developments

Compuestos indolicos con potencial anticancer: últimos desarrollos

Igor José dos Santos Nascimento', Max Denisson Maurício Viana ${ }^{2 *}$.

\section{RESUMO}

Objetivo: Compilar dados da literatura científica acerca dos principais compostos indólicos com potencial anticâncer desenvolvidos nos últimos anos. Métodos: Foram utilizados os seguintes bancos de dados: PubMed (US National Library of Medicine National Institute of Health), Science Direct, SciFinder e Bentham Science, no período de 2007 de 2020 com os descritores indole AND anticâncer. Os estudos elegíveis retratavam da temática da pesquisa, publicados em inglês com texto completo disponível. Resultados: Foi mostrado que os indóis são compostos que apresentam potente atividade contra diversas linhagens de tumor (MDA-MB-231; HL-60; CCRF-CEM; K-562, MOLT-4; RPMI-8226, dentre outras) inibindo diferentes mecanismos responsáveis pela manutenção ou propagação da neoplasia (inibição da polimerização dos microtúbulos; enzima topoisomerase I; e intercalação com DNA das células tumorais) apresentando variadas estruturas químicas: desde indóis substituídos com estruturas simplificadas, até híbridos moleculares. Adicionalmente, os resultados de concentração inibitória 50 (IC 50$)$ mostraram compostos com inibição na escala nanomolar e índice de seletividade significativo, representando uma classe promissora. Considerações finais: $O$ estudo fez um levantamento dos principais hits indólicos, passíveis de gerar novos compostos leads para a descoberta de fármacos com o objetivo de avançar nas pesquisas para produção de novos agentes antineoplásicos, com maior eficácia e menor incidência de efeitos colaterais.

Palavras-chave: Indóis, Anticâncer, Antineoplásico.

\begin{abstract}
Objective: To compile data from the scientific literature on the main indole compounds with anticancer potential developed in recent years. Methods: We used the following databases: PubMed, Science Direct, SciFinder and Bentham Science, in the period from 2007 to 2020, with the descriptors of AND anticancer indicators. The eligible studies portrayed in the research theme, published in english with full text available. Results: Research has shown that indoles are compounds that have a potent activity against several tumor strains (MDA-MB-231; HL-60; CCRF-CEM; K-562, MOLT-4; RPMI-8226 and among others) with inhibition of different mechanisms responsible for the maintenance or spread of the neoplasm (Inhibition of microtubule polymerization; inhibition of topoisomerase I and intercalation with tumor cell DNA) presenting varied chemical structures, from indoles replaced with simplified structures, to hybrids molecular. Additionally, the inhibitory concentration 50 ( $\left.\mathrm{IC}_{50}\right)$ showed compounds with inhibition on the nanomolar scale and an excellent selectivity index, representing a promising class. Final considerations: This study made a survey of the main indolic hits, capable of generating new lead compounds for the development of drugs with the objective of advancing research for the production of new antineoplastic agents, with greater efficiency and less incidence of side effects.
\end{abstract}

Keywords: Indole, Anticancer, Antineoplastic.

${ }^{1}$ Universidade Federal de Alagoas (UFAL), Maceió - AL.

2 Universidade Federal da Bahia (UFBA), Salvador - BA. *E-mail: max.viana@ufba.br

SUBMETIDO EM: 5/2020

ACEITO EM: 6/2020

PUBLICADO EM: $8 / 2020$ 


\section{RESUMEN}

Objetivo: recopilar datos de la literatura científica sobre los principales compuestos indólicos con potencial anticancerígeno desarrollados en los últimos años. Métodos: Se usaron las siguientes bases de datos: PubMed, Science Direct, SciFinder y Bentham Science, en el período 2007-2020 con los descriptores indole AND anticancer. Los estudios elegibles retrataron el tema de investigación, publicado en inglés con el texto completo disponible. Resultados: Se demostró que los indoles son compuestos con una potente actividad contra varias cepas tumorales (MDA-MB-231; HL-60; CCRF-CEM; K-562, MOLT-4; RPMI-8226, entre otros) que inhiben mecanismos responsables del mantenimiento o la propagación de la neoplasia (inhibición de la polimerización de microtúbulos; enzima topoisomerasa I e intercalación con el DNA de las células tumorales) con diversas estructuras químicas: indoles reemplazados por estructuras simplificadas hasta híbridos moleculares. Además, la concentración inhibitoria $50\left(\mathrm{IC}_{50}\right)$ mostraron compuestos con inhibición en la escala nanomolar e índice de selectividad significativo, que representa una clase prometedora. Consideraciones finales: El estudio realizó una encuesta de los principales golpes indólicos, capaces de generar nuevos compuestos de plomo para el descubrimiento de fármacos con el objetivo de avanzar en la investigación para la producción de nuevos agentes antineoplásicos, con mayor eficiencia y menor incidencia de efectos secundarios.

Palabras clave: Indol, Anticancerígeno, Antineoplásico.

\section{INTRODUÇÃO}

Câncer compreende o conjunto de mais de 100 doenças, caracterizado pelo crescimento anormal e desordenado das células, que pode evoluir e invadir tecidos normais, difundindo-se pelas diversas regiões do organismo; sendo a segunda maior causa de mortes no mundo, estimada em cerca de 9,6 milhões só no ano de 2018 (World Health Organization, 2020). Em razão da alta prevalência desta doença em todo o mundo, são crescentes os estudos de novos fármacos visando a ampliação do arsenal terapêutico e uma terapia com menor incidência de efeitos colaterais. Dentre os compostos estudados, os que apresentam o núcleo indólico ocupam posição de destaque no desenvolvimento de fármacos (FU C, et al., 2015).

$O$ anel indólico é um dos heterociclos biologicamente ativos de maior abundância na natureza em animais e humanos, a exemplo: o triptofano, serotonina e melatonina. Com relação às características químicas, o núcleo indólico é constituído de uma molécula bicíclica planar contendo um átomo de nitrogênio, apresentando 10 elétrons-T, sendo uma molécula aromática de acordo com a regra de Huckel. Adicionalmente, atua como base fraca (CHADHA N e SILAKARI O, 2017). Esses compostos são frequentemente descritos na literatura devido à ampla aplicabilidade para fins terapêuticos, tais como: anticonvulsivante, antidepressiva, antiviral, antimicrobiana, anti-inflamatória e principalmente antitumoral (CURY NM et al. 2019; SHERER C e SNAPE TJ, 2015). São notáveis os investimentos em pesquisas, tanto acadêmico quanto da indústria farmacêutica, visando o desenvolvimento de novos compostos com núcleos indólicos baseados em pequenas moléculas por apresentarem uma estrutura amplamente distribuída na natureza e com atividades antitumorais já previamente descritas na literatura (SHERER C e SNAPE TJ, 2015).

Nesse sentido, o presente estudo objetivou levantar dados na literatura acerca do desenvolvimento mais recente de compostos indólicos com potencial anticâncer.

\section{REVISÃO DA LITERATURA}

\section{Fisiopatologia do câncer}

Câncer é uma doença de origem genética, cuja alteração resulta na incapacidade de diferenciação celular, de modo que as células se proliferam de maneira rápida e desordenada alterando os processos de divisão celular. Esses genes especiais são denominados proto-oncogenes, que a princípio são inativos em células normais e, quando ativados, convertem-se em oncogenes, responsáveis pela ativação anormal dos genes que controlam o processo de mitose e crescimento celular, resultando em células malignas. Estas células são, então, denominadas cancerosas ou tumorais (DE ALMEIDA VL, et al., 2005). 
Nem todo tumor é formado de células neoplásicas, visto que de 1 a $10 \%$ do conteúdo são vasos sanguíneos. Logo, todo provimento energético do tumor é atribuído à vascularização nas adjacências. Durante o crescimento do tumor, alguns vasos sanguíneos são obstruídos, enquanto outros são formados, ramificando-se excessivamente ao redor.

A consequência desse processo é que algumas áreas do tumor são bem irrigadas, enquanto que outras não, reduzindo ou anulando o aporte de oxigênio e nutrientes em alguns locais. Assim, as células circunvizinhas aos vasos sanguíneos serão bem oxigenadas, e as mais distantes serão anóxicas e necróticas. As células que estão entre essas duas regiões são as células em. Isso explica resistência à quimioterapia em tumores sólidos, isto é, a dificuldade do fármaco em alcançar as células em hipóxia (OLIVEIRA RB e ALVES RJ, 2002).

\section{Indóis e sua atividade contra o câncer}

Os compostos indólicos estão presentes nos diversos sistemas biológicos, sendo uma classe de heterociclos bastante estudada devido ao seu potencial biológico e farmacológico. Os primeiros indóis com atividade anticâncer foram denominados de alcaloides da vinca (vincristina, vimblastina, vindesina e vinorelbina), utilizados até os dias de hoje no tratamento de vários tipos de câncer. Desde a descoberta desses compostos, são constantes os estudos visando a atividade anticâncer dessa classe de compostos (CHADHA N e SILAKARI O, 2017).

São vários os alvos celulares em que os compostos antineoplásicos agem, e que compreendem desde alteração no processo de divisão celular até intercalação com o ácido desoxirribonucleico (DNA) e inibição de enzimas essenciais para a manutenção dessa estrutura (ABDELMOEZ A, et al., 2017). Tendo conhecimento dos principais alvos, séries de compostos indólicos são constantemente planejadas e testadas frente a esses alvos celulares, apresentando derivados promissores que podem ser utilizados como leads para 0 desenvolvimento de fármacos antineoplásicos (ABDELMOEZ A, et al., 2017).

A polimerização dos microtúbulos é um dos principais processos mitóticos de replicação de células neoplásicas, e se tornou um alvo atraente para os pesquisadores que visam um novo fármaco anticâncer, principalmente aqueles que utilizam compostos derivados de indóis, já que a principal ação dos alcaloides da vinca consiste na inibição destas organelas (REGINA L, et al. 2018).

A enzima topoisomerase também desempenha importante controle da remodelação de cromatina, replicação, recombinação, mitose e transcrição de DNA (considerado um dos maiores alvos dos antineoplásicos, pois apresenta alta expressão em células cancerígenas), e já são descritos na literatura diversos compostos derivados de indóis que agem nessa enzima (SHERER C e SNAPE TJ, 2015). Os agentes antineoplásicos podem agir não somente inibindo a topoisomerase, mas também diretamente nas fitas de DNA por meio de um processo conhecido como intercalação de DNA, que resulta em mudanças na estrutura do mesmo, causando endurecimento, alongamento e o desenrolamento das hélices e, em consequência disso, ocorre a inibição do crescimento das células neoplásicas (LAFAYETTE EA, et al., 2017).

\section{Indóis contra câncer de mama}

Diversos estudos com diferentes substituições são planejados e sintetizados constantemente a fim de se descobrir um novo composto baseado em um núcleo indólico com atividade anticâncer. Utilizando como estrutura de partida o indol-3-carbinol (I3C), o composto (1) (Figura 1A), um tetra indol com um anel benzeno no centro da estrutura, capaz de induzir apoptose em linhagens celulares MDA-MB-231 (linhagem celular derivada de adenocarcinoma de mama humana com característica metastática) e outros tipos de neoplasias, com valor de $\mathrm{IC}_{50}=0,5 \mu \mathrm{M}$ (FU C, et al., 2015).

A dimerização de um indol parece ser uma importante estratégia para melhorar a atividade desses compostos, a saber o composto (2) (Figura 1B), um dímero simples de indol que apresentou valores de inibição entre $12-20 \mu \mathrm{M}$, no qual a diminuição do anel central de 6 para um de 5 membros, aumento da atividade do composto, gerando o composto (3) (Figura 1C), com $\mathrm{IC}_{50}=3,1 \mu \mathrm{M}$ sob linhagem celulares de MDA-MB-468 (linhagem basal e invasiva de carcinoma de mama humana) (ZHU J, et al., 2015). 
É constante a busca por novos indóis simplificados que apresentem atividade anticâncer. Os compostos (4) e (5) (Figura 1D e 1E) apresentaram potente atividade citotóxica frente a células cancerosas de MCF-7 (Michigan Cancer Foundation-7, uma linhagem celular derivada de adenocarcinoma de mama humana com característica tumorigênica), com $\mathrm{IC}_{50}=3,78$ e 6,37 $\mu \mathrm{M}$ respectivamente, sendo proposto um modelo de rigidificação molecular para aumentar a atividade desses compostos (JI XY, et al., 2014).

Outro composto apresentou uma elevada citotoxicidade contra células tumorais MCF-7, com Gl 50 (concentração do agente que causa diminuição de $50 \%$ no crescimento celular líquido) $=58.5 \mu \mathrm{M}$, foi o composto (6) (Figura 1F), com uma atividade melhor que a do padrão utilizado, o gefitinib, que apresentou $\mathrm{Gl}_{50}=89,7 \mu \mathrm{M}$, constatando-se ainda uma atividade sinérgica entre os dois, mostrando ser uma associação vantajosa. Essa atividade foi atribuída ao grupo benzila ligado ao nitrogênio propondo ser um ótimo composto lead para o descobrimento de agentes antitumorais (KIM YJ, et al., 2017).

Os compostos (7) (Figura 1G), com EC 50 (concentração efetiva em reduzir $50 \%$ da viabilidade celular) $=$ $0,3 \mu \mathrm{M}$, os compostos (8) $\left(E C_{50}=0,2 \mu \mathrm{M}\right)$, (9) $\left(E_{50}=0,3 \mu \mathrm{M}\right)$ e (10) $\left(E C_{50}=0,2 \mu \mathrm{M}\right)$, mostrados na Figura $\mathbf{1 H}, \mathbf{1}$ e $\mathbf{1 J}$, respectivamente, apresentaram atividade antiproliferativa e concentrações submicromolar, em linhagens celulares de câncer de mama (MCF-7), nas quais os compostos mais ativos da série foram aqueles que apresentaram um grupo anisil ligado ao carbono 2 do núcleo indólico (SPALLAROSSA A, et al., 2015).

Um alvo importante desses compostos é a inibição da polimerização dos microtúbulos. O indol derivado da acrilamida (11) (Figura 1K) ligado a um grupo 3,4,5-trimetoxstiril apresentou atividade de $\mathrm{IC}_{50}=36,3 \mu \mathrm{M}$ frente a linhagens celulares MCF-7, com baixa toxicidade, e atividade em concentração menor que 20 micromolar conta linhagem de células HL-60 $\left(\mathrm{IC}_{50}=5,1 \mu \mathrm{M}\right)$, demonstrando o potencial anticâncer desses compostos (BAYTAS S, et al., 2014).

Esse grupo é de fundamental importância, visto que o composto derivado de resveratrol (12) (Figura 1L) apresentou o mesmo grupo trans-3,4,5-trimetoxistiril, com resultados de $\mathrm{Gl}_{50}=0,25 \mu \mathrm{M}$, frente a células HS 578T (linhagem celular de câncer de mama mais agressiva), sendo essencial a presença desse grupo para atividade antineoplásica (PENTHALA NR, et al., 2015).

Um método amplamente utilizado para a síntese de compostos anticâncer é a hibridação molecular, que consiste numa estratégia de modelagem molecular de fármacos, por meio do qual se tem a junção de dois grupamentos farmacofóricos em uma só estrutura, formando um novo composto dual, misto ou duplo, caracterizado como um híbrido molecular com propriedades farmacológicas de ambas as estruturas unidas, e em consequência disso, uma melhor e mais atraente atividade biológica (NEPALI K, et al., 2014).

Essa estratégia de modificação molecular foi empregada na síntese da tiazocumarina (13) (Figura 1M) testada em diferentes tipos de linhagens celulares de câncer de mama, apresentando $\mathrm{Gl}_{50}=-37,04 \mu \mathrm{M}$ sob células MDA-MB-231/ATCC (tipo celular de câncer de mama enriquecido com fatores de crescimento epidérmico) e inibição de células tumorais entre 55-99\% (GALI R, et al., 2015).

Outro híbrido molecular que apresentou ótima atividade foi indol ligado a um imidazol. A adição de um bromo no composto (14) (Figura 1N) melhorou atividade, com menos efeitos tóxicos sobre cardiomiócitos e fibroblatos, sendo ativo em linhagens de câncer MCF-7 resistente, com IC $\mathrm{C}_{50}=18,8 \mu \mathrm{M}$, podendo ser um promissor candidato a fármaco nos testes in vivo (MAHAL K, et al., 2016).

Já o composto (15) (Figura 10) apresentou uma atividade de $42 \%$ inibição da tubulina em linhagens celulares de MCF-7, com valor de $\mathrm{IC}_{50}=0,29 \mu \mathrm{M}$ e frente a células MDA-MB-231, com IC $\mathrm{C}_{50}=10,35 \mu \mathrm{M}$, sendo essa atividade atribuída à junção de uma pirimidina e um indol, associado a um grupo de alta densidade eletrônica ligado a carbonila do indol, que aumentou a atividade do composto (DIAO PC, et al., 2017). Com a utilização de uma andrografolida e um indol, obteve-se uma promissora atividade anticâncer com o composto (16) (Figura 1P), com valores de $\mathrm{IC}_{50}$ de $1,85 \mu \mathrm{M}$ frente a linhagens celulares de MCF-7, sendo essencial a ausência de uma hidroxila livre, um éter ou éster no C14 melhorava a atividade dos compostos, gerando assim o composto (16) como mais promissor da série (SONG Y, et al., 2015). 
Figura 1 - Indóis com atividade frente a linhagens celulares câncer de mama.

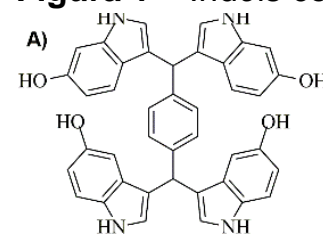

(1)

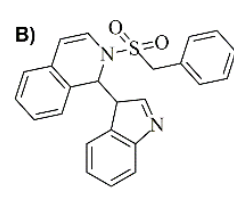

(2)

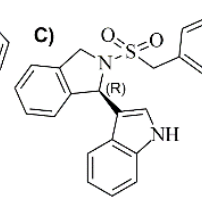

(3)

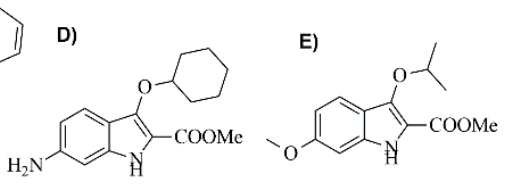

(5)

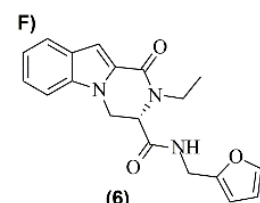

(6)

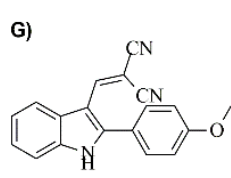

(7)

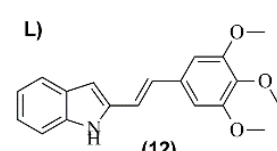

(12)

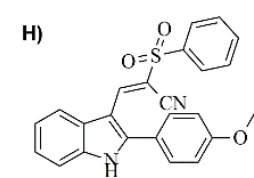

(8)

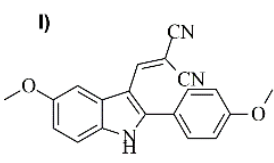

(9)

(4)

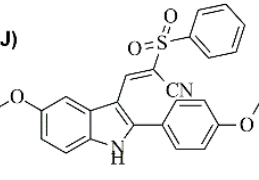

(10)

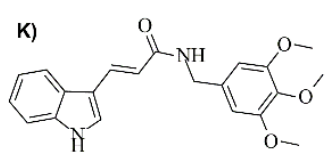

(11)

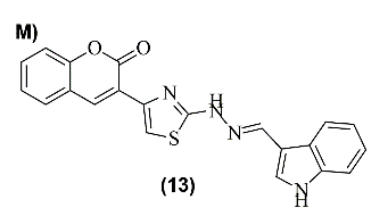

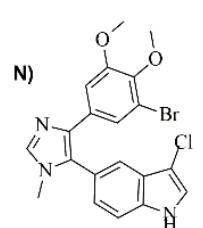

(14)

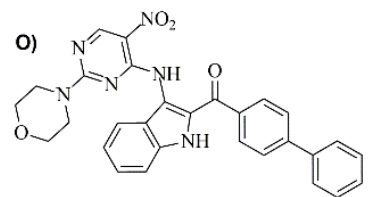

(15)

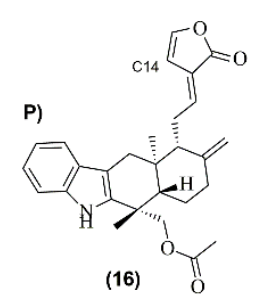

Fonte: NASCIMENTO IJS, et al., 2020. Baseado em: FU C, et al., 2015; ZHU J, et al., 2015; Ji XY, et al., 2014; KIM YJ, et al., 2017; SPALLAROSSA A, et al., 2015; BAYTAS S, et al., 2014; PENTHALA NR, et al., 2015 ; GALI R, et al., 2015; MAHAL K, et al., 2016; DIAO PC, et al., 2017 ; e SONG Y, et al., 2015.

\section{Indóis contra leucemia}

Como mostrado nos compostos contra o câncer de mama, alterações simples no composto indólico (17) (Figura 2A) apresentou significativa atividade contra leucemia também. Esse composto com estrutura simplificada induziu baixa toxicidade em inibir células de linhagem parental de leucemia linfoide aguda (CCRFCEM, Gl $\left.I_{50}=0,03 \mu \mathrm{M}\right), \mathrm{HL}-60\left(\mathrm{Gl}_{50}=1,5 \mu \mathrm{M}\right), \mathrm{K}-562\left(\mathrm{Gl}_{50}=1,5 \mu \mathrm{M}\right), \mathrm{MOLT}-4\left(\mathrm{Gl}_{50}=0,04 \mu \mathrm{M}\right)$, RPMI-8226 $\left(\mathrm{Gl}_{50}=0,01 \mu \mathrm{M}\right)$, SR $\left(\mathrm{Gl}_{50}=0,02 \mu \mathrm{M}\right)$ (SHAVETA P, et al., 2014).

A hibridação molecular também é uma estratégia utilizada para o planejamento desses compostos. Utilizando um indol acoplado a dois núcleos furânicos (18) (Figura 2B) em sua estrutura, houve uma significativa atividade anticâncer frente a uma linhagem celular originada de paciente com leucemia promielocítica aguda (HL-60), com IC $\mathrm{IC}_{50}=50 \mu \mathrm{M}$ (ZHUANG SH, et al., 2013).

Compostos derivados de beta-carbolina mostraram citotoxicidade, intercalação com DNA e inibição da topoisomerase I e II, demonstrado pelo composto (19) (Figura 2C), apresentando $\mathrm{IC}_{50}=0,78 \mu \mathrm{M}$, atribuído ao fato de possuir uma estrutura planar aromática da beta-carbolina (CHANG SM, et al., 2017). Os compostos (20) e (21) (Figura 2D e 2E) apresentaram resultados significativos (com $\mathrm{IC}_{50}=0,3 \mu \mathrm{M}$ e $\mathrm{IC}_{50}=5,60 \mu \mathrm{M}$, respectivamente) e uma potente atividade antiproliferativa por inibir a proteína Bcl-2, que é expressa em linhagens celulares de câncer, isso principalmente por apresentar o anel oxadiazólico unido ao indol, fornecendo novos leads para o desenvolvimento de fármacos (HAMDY R, et al., 2017).

$\mathrm{O}$ indol isolado da Uncaria rhynchophylla, a corynantheidine (22) (Figura 2F), apresentou valor de $\mathrm{IC}_{50}=$ 13,96 $\mu \mathrm{M}$ frente a linhagem celular de leucemia, HL-60 (NDAGIJIMANA A, et al., 2013).

Um outro estudo que revelou a atividade anticâncer de derivados indólicos foi o realizado por Cury NM et al. (2019), realizando a síntese de uma nova série de indóis 3-substituídos e 3,6-dissubstituídos-2-carboalcoxi, bem como a elucidação de seu mecanismo de ação e efetividade frente a linhagens celulares de leucemia. Assim, o composto (23) (Figura 2G) foi apresentado como mais promissor, com atividade de $\mathrm{IC}_{50}$ frente a células de leucemia linfoblástica aguda (CCRF-CEM) de $0,2 \mu \mathrm{M}$, e contra células de linhagem celular de leucemia aguda (RS4) de 0,3 $\mu \mathrm{M}$. Adicionalmente, foi mostrado que o mecanismo de ação desse composto está relacionado à inibição da tubulina, gerando parada no ciclo $\mathrm{G} 2 / \mathrm{M}$, resultando em dano no DNA e consequentemente apoptose, isso de maneira dose-dependente. Por fim, a avaliação in vivo mostrou aumento da sobrevida dos ratos, indicando um composto promissor para a terapia anticâncer. 
Figura 2 - Indóis com atividade frente a linhagens celulares de leucemia.<smiles>CC(=N)/C(=C/c1cn(C(=O)c2ccc(Cl)cc2)c2ccccc12)C(=O)Nc1ccc(Cl)cc1</smiles>

(17)
B)<smiles>OCc1ccc(Cn2c3ccccc3c3oc(CO)cc32)o1</smiles>

C)<smiles>Cc1c(CO)c(CO)c2n1CCc1c-2[nH]c2ccccc12</smiles>

(20)<smiles>Clc1cccc(Nc2nnc(-c3c[nH]c4ccccc34)o2)c1</smiles>

(19)<smiles>O=[N+]([O-])c1ccccc1Nc1nnc(-c2c[nH]c3ccccc23)o1</smiles>

(21)<smiles>CC[C@H]1CN2CCc3c([nH]c4ccccc34)C2C[C@H]1/C(=C\OC)C(=O)OC</smiles>

(22)<smiles>COC(=O)c1[nH]c2cc(OC)ccc2c1-c1ccc(C(F)(F)F)cc1</smiles>

(23)

Fonte: NASCIMENTO IJS, et al., 2020. Baseado em: SHAVETA P, et al., 2014; ZHUANG SH, et al., 2013; CHANG SM, et al., 2017; HAMDY R, et al., 2017; NDAGIJIMANA A, et al., 2013 ; CURY NM et al. 2019.

\section{Indóis contra câncer de pulmão}

Em ensaios contra linhagem parental de adenocarcinoma de pulmão humano (A-549), os compostos (25) e (26) (Figura 3A e 2B) são híbridos de indol-pirazolona que apresentaram uma ótima atividade, com $\mathrm{IC}_{50}=$ $1,0 \mu \mathrm{M}$ e IC $50=3,4 \mu \mathrm{M}$, respectivamente, atribuído ao núcleo pirazolona em sua estrutura (BIRADAR JS e SASIDHAR BS, 2011).

El-Sharief MAS, et al. (2019) buscando a descoberta de novos compostos anticâncer, sintetizaram uma nova série de indóis conjugados com sulfonamida de isatina e espiroisatinas, avaliando a atividade antiproliferativa contra o receptor do fator de crescimento epidérmico (EGFR), um dos alvos explorados na descoberta de novos compostos contra o câncer de pulmão.

Nesse contexto, os compostos (26), (27) e (28), apresentados na Figura 3C, 2D e 2E, respectivamente, mostraram serem os mais promissores $\left(\mathrm{IC}_{50}=0,0191 ; 0,0266\right.$ e $0,0253 \mu \mathrm{M}$, respectivamente), com melhores resultados que o compostos padrão, Lapatinib, com IC $\mathrm{I}_{50}$ de $0,028 \mu \mathrm{M}$. Assim, esse estudo apresentou novos compostos que podem ser explorados no desenvolvimento de um novo agente contra o câncer de pulmão.

Youssif, BGM, et al. (2017) reportaram a síntese de novos compostos apresentando o núcleo indol acoplado à pirazina seguida de sua avaliação contra o receptor EGFR. Nesse contexto, foi mostrado que os compostos (29) e (30), mostrados na Figura 3F e 2G, respectivamente, apresentaram os resultados mais promissores $\left(\mathrm{IC}_{50}=2,4 \pm 1,2\right.$ e 1,7 $\pm 0,5 \mu \mathrm{M}$, respectivamente).

Adicionalmente, os compostos apresentaram os melhores resultados no ensaio antioxidante $\left(\mathrm{IC}_{50}=3,6 \mathrm{e}\right.$ $1,48 \mu \mathrm{M}$, respectivamente), mostrando que a hibridização entre essas duas classes de moléculas pode ser promissora como estratégia na descoberta de novos compostos anticâncer, em especial contra o câncer de pulmão. 
Figura 3 - Indóis com atividade frente a linhagens celulares de câncer de pulmão.<smiles>CC1=NNC(=O)C1=Cc1c(-c2ccccc2)[nH]c2ccc(Cl)cc12</smiles>

(24)<smiles>CC1=NNC(=O)C1=Cc1c[nH]c2ccc(Cl)cc12</smiles>

(25)<smiles>CC(=O)Nc1cccc(C(=O)/C=C2\C(=O)Nc3ccc(S(=O)(=O)N4CCOCC4)cc32)c1</smiles>

(26)
D)<smiles>N#CC(C#N)=C1C(=O)Nc2ccc(S(=O)(=O)N3CCOCC3)cc21</smiles><smiles>O=C(O)C1=C2c3cc(S(=O)(=O)N4CCOCC4)ccc3NC2NC1=O</smiles>

(28)
F)<smiles>O=c1[nH]c(Cc2ccccc2)cn2c1cc1cc(Cl)ccc12</smiles>

(29)
G)<smiles>Cc1c2cc(Cl)ccc2n2cc(Cc3ccccc3)[nH]c(=O)c12</smiles>

Fonte: NASCIMENTO, IJS, et al., 2020. Baseado em: BIRADAR JS e SASIDHAR BS, 2011; EL-SHARIEF MAS, et al. 2019; e YOUSSIF, BGM, et al., 2017.

\section{Indóis contra melanoma}

Um dos compostos testados frente a linhagens celulares de melanoma foi o derivado de betacarbolida. $O$ composto (31), mostrado na Figura 4A, apresentou importante atividade nos diferentes tipos de linhagens celulares, com valores de $\mathrm{Gl}_{50}$ variando entre 1,60-3,69 $\mu \mathrm{M}$. Já o composto (32) (Figura 4B) apresentou inibição em 45 tipos diferentes de linhagens celulares, inclusive as linhagens de melanoma, com Gl 50 variando entre 1,19-4,03 $\mu \mathrm{M}$ demonstrando que os derivados da beta-carbolida aparentam ser uma classe promissora no desenvolvimento de fármacos anticâncer (SAMUNDEESWARI S, et al., 2017).

Wang Q, et al. (2018) testaram novos compostos indólicos com alta potência frente a linhagens celulares malignas de melanoma (A375). Nesse estudo, foi descoberto o composto (33) (Figuras 4C), que além de apresentar potente atividade antiproliferativa contra células $A 375\left(\mathrm{IC}_{50}=0,7 \pm 0,2 \mu \mathrm{M}\right)$, demostrou ainda nos estudos in vivo a capacidade da molécula inibir a proliferação do tumor, sem toxicidade aparente, representando um novo composto que pode ser explorados em outros ensaios pré-clínicos com potencial promissor.

Figura 4 - Indóis com atividade frente a linhagens celulares de melanoma.

A)<smiles>c1ccc2[nH]c(-c3ccc(-c4nccc5c4[nH]c4ccccc45)cc3)nc2c1</smiles>

(31)
B)<smiles>CC1c2ccccc2NC1c1ccc(C2NCCC3c4ccccc4NC32)cc1</smiles>

(32)
C)<smiles>Oc1c(CN2CCCC2)cc(Cn2ccc3cc(F)ccc32)c2cccnc12</smiles>

(33)

Fonte: NASCIMENTO IJS, et al., 2020. Baseado em: SAMUNDEESWARI S, et al., 2017; e WANG Q, et al., 2018. 


\section{Indóis contra hepatoma}

Contra hepatoma, os compostos (34) e (35), mostrados na figura $5 \mathrm{~A}$ e $\mathrm{B}$, respectivamente, com $\mathrm{IC}_{50}=$ $6,63 \mu \mathrm{M}$ e $2,50 \mu \mathrm{M}$, respectivamente, apresentaram atividade mais promissora que Sorafenib (um antineoplásico presente no mercado), com $\mathrm{IC}_{50}=14,95 \mu \mathrm{M}$ frente a linhagens celulares de HepG2 (um tipo de linhagem celular cancerígena de tecido hepático), com destaque para a atividade de (35), que apresentou em sua estrutura a adição de um flúor no carbono 3 do indol, melhorando sua atividade (WU Z, et al., 2014).

Outro composto promissor é o hibrido de indol com esteroide (36) (Figura 5C), o qual foi capaz de inibir linhagens celulares de Bel 7404, um tipo celular de hepatoma humano com expressão mutante da transcriptase reversa (CUI J, et al., 2015). A hibridação entre um indol e uma piranochalcona (37) (Figura 5D) se mostrou eficaz frente a linhagens celulares de HepG2, com $\mathrm{IC}_{50}=0,22 \mu \mathrm{M}$ propondo que o principal mecanismo é através da inibição da polimerização de microtúbulos (WANG G, et al., 2014).

Outros indóis que apresentaram atividade contra hepatoma humano (Hep-G2) foram os derivados (38), (39), (40), e (41), mostrados na Figura 5E, 5F, 5G, e 5H, respectivamente, constituídos de híbridos moleculares de indol e uma benzoxazepina com $\mathrm{Gl}_{50}=10 \mu \mathrm{M}$, no qual a introdução de halogênios mais eletronegativos na fenila aumentou a citotoxicidade dos compostos (SINGH R, et al., 2017).

O estudo de Li Z, et al. (2018) propôs a síntese de novos compostos N-heterocíclicos com avaliação anticâncer frente a linhagens celulares de hepatoma humano (HepG2), apresentando o composto (42) (Figura 5I) como mais promissor, com atividade de $I_{50}$ de $1,96 \pm 0,39 \mu \mathrm{M}$, e o principal mecanismo relacionado à inibição da Topoisomerase I. Adicionalmente, os estudos in vivo demonstraram que o composto teve a capacidade de suprimir o crescimento do tumor sem apresentar efeitos colaterais aparentes.

Figura 5 - Indóis com atividade frente a linhagens celulares de hepatoma.

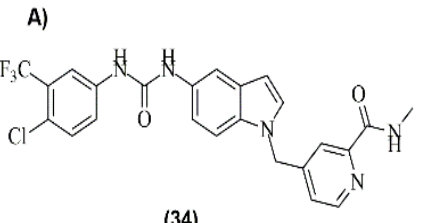

(34)

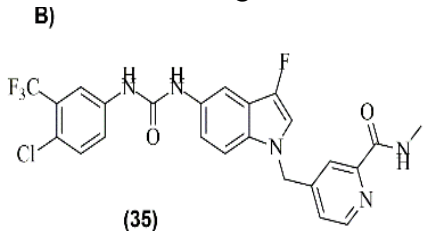

(35)

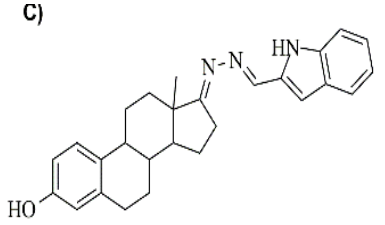

(36)

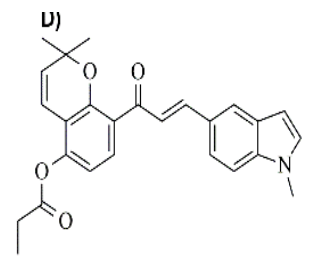

(37)

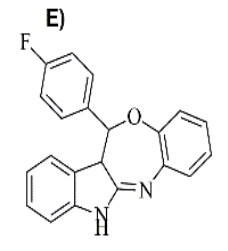

(38)

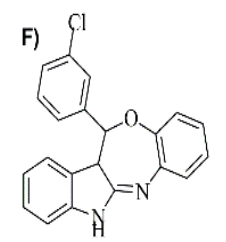

(39)

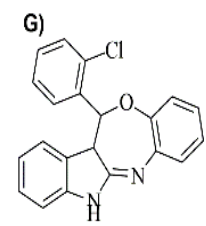

(40)

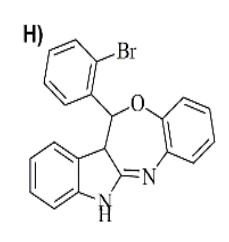

(41)

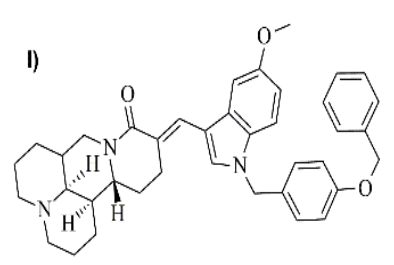

(42)

Fonte: NASCIMENTO IJS, et al., 2020. Baseado em: WU Z, et al., 2014; CUI J, et al., 2015; WANG G, et al., 2014; SINGH R, et al., 2017 ; LI Z, et al., 2018.

\section{Indóis contra glioblastoma, osteosarcoma e adenocarcinoma de ovário e câncer de próstata.}

Um composto promissor para na quimioterapia resistente em culturas de células de glioblastoma é o composto (43) (Figura 6A), com $\mathrm{EC}_{50}=50 \mu \mathrm{M}$ demonstrado num estudo de revisão na qual a forma dimerizada, com a adição do grupo 2-fenil, aumentou a atividade tanto do pró-farmaco quanto da forma ativa, e ao substituir o indol por um tiofeno, ocorre uma diminuição da atividade (SHERER C, et al., 2017).

Já contra osteosarcoma, a espécie vegetal Alstonia Yunnanensis apresenta compostos indólicos como metabólitos secundários, cujos compostos (44), (45) e (46), mostrados na Figura 6B, 6C e 6D, respectivamente, proporcionaram uma potente atividade anticâncer frente a linhagens celulares amplamente utilizadas e caracterizadas em modelos in vitro de osteosarcoma (SOSP-9607, MG-63, Saos-2, M663), com valores de IC 50 de variando entre 3,2-5,8 $\mu \mathrm{M}$ - Figura 13 (LI CJ, et al., 2017). 
O estudo realizado por Regina L, et al. (2018) visou a síntese de novos compostos indólicos substituídos em posições estratégicas, de modo a avaliar a eficácia dessas modificações contra linhagens celulares multirresistentes de adenocarcinoma de ovário (NCI/ADR-RES). Assim, os autores apresentaram os compostos (47) e (48) (Figura 6E e 6F), com valores de citotoxicidade de $I_{50}$ contra as linhagens tumorais na escala de nanomolar (7,5 \pm 2 e $34 \pm 8$, respectivamente), representando novos scaffolds que podem ser utilizando na pesquisa de otimização de novos compostos com potencial anticâncer.

O composto (49) (Figura 6G), com a introdução de um grupo mais eletronegativo na posição para da fenila aumentou a atividade contra linhagens celulares de câncer de próstata (DU154), com IC $\mathrm{C}_{50}=0,14 \mu \mathrm{M}$ sugerindo que o composto induz apoptose nas células (GUGGILAPU SD, et al., 2017).

Buscando por novos compostos com atividade anticâncer, em especial contra o câncer de próstata, He Z et al., (2019) sintetizaram uma nova série de híbridos moleculares de indóis e tiossemicarbazonas. Nesse contexto, os autores descobriram o composto (50) (Figura 6H) como mais ativo da série, apresentando maior seletividade contra linhagem celular câncer de próstata derivada de metástase óssea (PC3), com IC $\mathrm{C}_{50}$ de 0,14 $\mu \mathrm{M}$. Assim, os autores atribuíram a atividade melhorada do composto devido ao efeito sinérgico das duas classes de compostos. Adicionalmente, foi mostrado que a inibição da proliferação é por meio de indução de apoptose além de agir no ciclo celular.

Figura 6 - Indóis com atividade contra linhagens celulares de glioblastoma e osteosarcoma, adenocarcinoma de ovário e câncer de próstata.

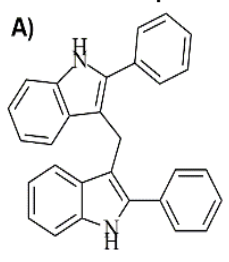

(43)

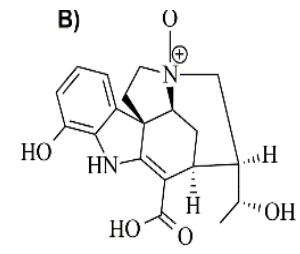

(44)

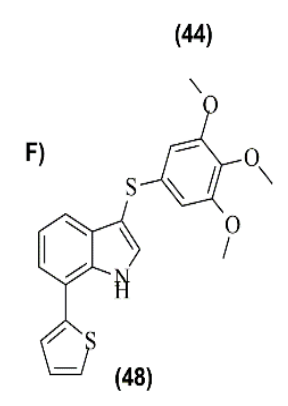

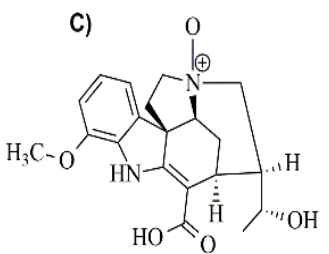

(45)

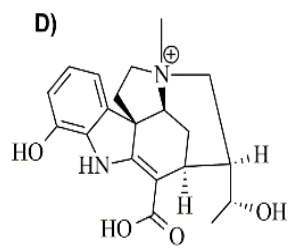

(46)

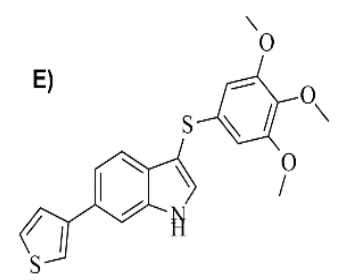

(47)
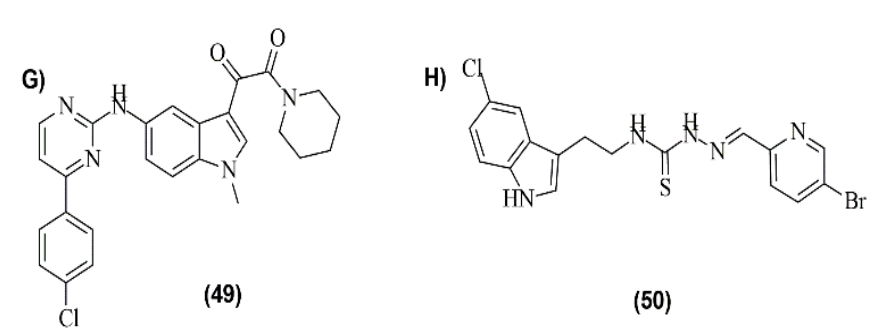

Fonte: NASCIMENTO IJS, et al., 2020. Baseado em: SHERER C, et al., 2017; LI CJ, et al., 2017 ; GUGGILAPU SD, et al., 2017; HE Z et al., 2019; e REGINA L, et al., 2018.

\section{CONSIDERAÇÕES FINAIS}

Os compostos indólicos, como observado, são destaque nos testes experimentais por apresentarem potente atividade antiproliferativa com valores de concentração inibitória de células cancerígenas na escala nanomolar. A ação dessa classe de compostos mostrou ser efetiva nos diversos tipos de câncer, incluindo os de maior letalidade, como o de pulmão, e de mais alta prevalência mundial, como o de mama. Diferentes estruturas moleculares foram capazes de produzir resultados significativos, desde moléculas estruturalmente simplificadas às mais complexas formadas por dímeros ou híbridos moleculares com diversos heterociclos. Além destes, os isolados de produtos naturais também tiveram resultados promissores sobre várias linhagens tumorais. A partir do levantamento aqui descrito dos principais hits indólicos, foi possível demonstrar estruturas passíveis de gerar novos compostos leads, visando a obtenção de um novo derivado antitumoral que apresente toxicidade seletiva, além de reforçar a atenção de fundações de financiamento para fomentar pesquisas nesta área de desenvolvimento. 


\section{REFERÊNCIAS}

1. ABDELMOEZ A, et al. Screening and identification of molecular targets for cancer therapy. Cancer Letters, $2017, \mathrm{v}$. 387, p. 3-9.

2. BAYTAS S, et al. Synthesis, biological evaluation and molecular docking studies of trans-indole-3-acrilamide derivatives, a new class of tubulin polymerization inhibitors. Bioorganic \& Medicinal Chemistry, 2014, v. 22, p. 30963104.

3. BIRADAR JS, SASIDHAR BS. Solvent-free, microwave assisted Knoevenagel condensation of novel 2,5-disubstituted indole analogues and their biological evaluation. European Journal of Medicinal Chemistry, 2011, v. 46, p. 6112-6118.

4. CHADHA N, SILAKARI O. Indoles as therapeutics of interest in medicinal chemistry: Bird's eye view. European Journal Of Medicinal Chemistry, 2017, v. 134, p. 159-184.

5. CHANG S-M, et al. Novel indolizino[8,7-b]indole hybrids as anti-small cell lung câncer agents: Regioselective modulation of topoisomerase II inhibitory and DNA crosslinking activities. European Journal of Medicinal Chemistry, 2017, v. 127, p. 235-249.

6. CUI J, et al. Synthesis, characterization and antitumor activities of some steroidal derivatives with side chain of 17 hydrazone aromatic heterocycle. Steroids, 2015, v. 95, p. 32-38.

7. CURY NM, et al. Synthesis and evaluation of 2-carboxy indole derivatives as potent and selective anti-leukemic agents. European Journal of Medicinal Chemistry, 2019, v. 181.

8. DE ALMEIDA VL, et al. Câncer e agentes antineoplásicos ciclo-celular específicos e ciclo-celular não específico que interagem com o DNA: Uma introdução. Química Nova, 2005, Vol. 28, No. 1, p. 118-129.

9. DIAO PC, et al. Synthesis and biological evaluation of novel indole-pyrimidine hybrids bearing morpholine and thiomorpholine moieties. European Journal of Medicinal Chemistry, 2017, v. 134, p. 110-118.

10. EL-SHARIEF AMS, et al. Design, synthesis, molecular docking and biological activity evaluation of some novel indole derivatives as potent anticancer active agents and apoptosis inducers. Bioorganic Chemistry, 2019, v. 85, n. January, p. 399-412.

11. FU CW, et al. Anticancer efficacy of unique pyridine-based tetraindoles. European Journal of Medicinal Chemistry. 2015, v. 104, p. 65-176.

12. GALI R, et al. One-pot multicomponent synthesis of indole incorporated thiazolilcoumarins and their antibacterial, anticâncer and DNA cleavage studies. Bioorganic \& Medicinal Chemistry Letters, 2015, v. 25, p. 106-112.

13. GUGGILAPU SD, et al. Synthesis of C5-tethered indolyl-3-glyoxylamide derivatives as tubulina polymerization inhibitors. European Journal of Medicinal Chemistry, 2017, v. 128, p. 1-12.

14. HAMDY R, et al. Synthesis and evaluation of 5-(1H-indol-3-yl)-N-aryl-1,3,4-oxadiazol-2- amines as Bcl-2 inhibitory anticancer agentes. Bioorganic \& Medicinal Chemistry Letters, 2017, v. 27, p. 1037-1040.

15. HE Z, et al. Novel thiosemicarbazone derivatives containing indole fragment as potent and selective anticancer agent. European Journal of Medicinal Chemistry, 2019, v. 184, p. 111764.

16. Jl X-Y, et al. Design, synthesis and antiproliferative activity of a novel class of indole-2-carboxilate derivatives. European Journal of Medicinal Chemistry, 2014, v. 83, p. 409-418.

17. KIM YJ, et al. Design, synthesis, and biological evaluation of novel 1-oxo-1,2,3, 4-tetrahydropyrazino[1,2-a]indole-3 carboxamide analogs in MCF-7 and MDA-MB-468 breast cancer cell lines. Bioorganic \& Medicinal Chemistry Letters. 2017, v. 27, p. 607-611.

18. LAFAYETTE EA, et al. Synthesis of novel indole derivatives as promising DNA-binding agents and evaluation of antitumor and antitopoisomerase I activities. European Journal of Medicinal Chemistry, 2017, v. 136, p. 511-522.

19. LI C-J, et al. Cytotoxic monoterpenoid indole alkaloids from Alstonia yunnanensis Diels. Fitoterapia, 2017, v. 117, 7983.

20. LI Z, et al. Design, synthesis, biological evaluation and structure-activity relationship of sophoridine derivatives bearing pyrrole or indole scaffold as potential antitumor agents. European Journal of Medicinal Chemistry, 2018, v. 157, p. 665-682.

21. MAHAL K, et al. Combretastatin A-4 derived 5-(1-methyl-4-phenyl-imidazol-5-yl) indoles with superior cytotoxic and anti-vascular effects on chemoresistant cancer cells and tumors. European Journal of Medicinal Chemistry, $2016, \mathrm{v}$. 118 , p. 9-20.

22. NDAGIJIMANA A, et al. A review on indole alkaloids isolated from Uncariarhynchophylla and their pharmacological studies. Fitoterapia, 2013, v. 86, p. 35-47.

23. NEPALI K, et al. Rational approaches, design strategies, structure activity relationship and mechanistic insights for anticancer hybrids. European Journal of Medicinal Chemistry, 2014, v. 77, p. 422-487.

24. OLIVEIRA RB, ALVES RJ. Antineoplásicos biorredutíveis: Uma nova alternativa para o tratamento de tumores sólidos. Química Nova. 2002, Vol 25, No 6, 976-984.

25. PENTHALA NR, et al. Heteroaromatic analogs of the resveratrol analog DMU-212 as potente anti-cancer agentes. Bioorganic \& Medicinal Chemistry Letters, 2015, v. 25, p. 2763-2767.

26. REGINA GLA, et al. New 6- and 7-heterocyclyl-1H-indole derivatives as potent tubulin assembly and cancer cell growth inhibitors. European Journal of Medicinal Chemistry, 2018, v. 152, p. 283-297.

27. SAMUNDEESWARI S, et al. Design and synthesis of novel phenyl -1, 4-beta-carboline-hybrid molecules as potential anticancer agentes. European Journal of Medicinal Chemistry, 2017, v. 128, p. 123-139.

28. SHAVETA P, et al. Structural optimization of indole based compounds for highly promising anti-cancer activities: Structure activity relationship studies and identification of lead molecules. European Journal of Medicinal Chemistry, 2014 , v. 74 , p. 440-450. 
29. SHERER C, SNAPE TJ. Heterocyclic scaffolds as promising anticancer agents against tumours of the central nervous system: Exploring the scope of indole and carbazole derivatives. European Journal of Medicinal Chemistry, $2015, \mathrm{v}$. 97, p. 552-560.

30. SHERER C, et al. Preliminary SAR on indole-3-carbinol and related fragments reveals a novel anticancer lead compound against resistant glioblastoma cells. Bioorganic \& Medicinal Chemistry Letters, 2017, v. 27,p.1561-1565.

31. SINGH R, et al. Indole-fused benzooxazepines: a new structural class of anticancer agentes. Future Science OA, 2017, v. 3, No. 1, p.168.

32. SONG Y, et al. Synthesis and anticancer activity of some novel indolo[3,2-b]andrographolide derivatives as apoptosisinducing agentes. European Journal of Medicinal Chemistry, 2015, v. 90, p. 695-706.

33. SPALLAROSSA A, et al. Unconventional Knoevenagel-type indoles: Synthesis and cell-based studies for the identification of pro-apoptotic agentes. European Journal of Medicinal Chemistry, 2015, v. 102, p. 648-660.

34. WANG G, et al. Design, synthesis and biological evaluation of a series of pyrano chalcone derivatives containing indole moiety as novel anti-tubulin agentes. Bioorganic \& Medicinal Chemistry, 2014, v. 22, p. 2060-2079.

35. WANG Q, et al. Synthesis and biological evaluation of indole-based UC-112 analogs as potent and selective survivin inhibitors. European Journal of Medicinal Chemistry, 2018, v. 149, p. 211-224.

36. WHO (World Health Organization). Cancer. Disponível em: <https://www.who.int/health-topics/cancer\#tab=tab_1>. Acesso em: 02 de Jun. 2020.

37. WU Z, et al. Design, synthesis and biological evaluation of indole derivatives as novel inhibitors targeting B-Raf kinase. Chinese Chemical Letters, 2014, v. 25, p.351-354.

38. YOUSSIF BGM, et al. Design, synthesis, mechanistic and histopathological studies of small-molecules of novel indole2-carboxamides and pyrazino[1,2-a]indol-1(2H)-ones as potential anticancer agents effecting the reactive oxygen species production. European Journal of Medicinal Chemistry, 2018, v. 146, p. 260-273.

39. ZHU J, et al. Synthesis, molecular modeling, and biological evaluation of novel RAD51 inhibitors. European Journal of Medicinal Chemistry, 2015, v. 96, p. 196-208.

40. ZHUANG SH, et al. Synthesis and anticancer activity of 2,4-disubstituted furo[3,2-b] indole derivatives. European Journal of Medicinal Chemistry, 2013, v. 66, p. 466-479. 